\title{
PHYTOCHEMICAL CONTENT AND ANTIOXIDANT POTENTIAL OF DIFFERENT ORGANS OF EGGPLANT (SOLANUM MELONGENA L.) GROWN IN WEST JAVA-INDONESIA
}

\author{
IRDA FIDRIANNY*, SITI WINARSIH, KOMAR RUSLAN
}

Department of Pharmaceutical Biology, Pharmaceutical Biology Research Group, School of Pharmacy, Bandung Institute of Technology, Bandung, Indonesia. Email: irdafidrianny@gmail.com

Received: 20 March 2017, Revised and Accepted: 27 April 2017

\section{ABSTRACT}

Objectives: The goals of this research were to evaluate antioxidant potential from different organs of eggplant (Solanum melongena L.) using two antioxidant testing methods which were 2,2-diphenyl-1-picrylhydrazyl (DPPH) and ferric reducing antioxidant power (FRAP) and correlation of total phenolic and flavonoid content with their inhibitory concentration $50 \%\left(\mathrm{IC}_{50}\right)$ of DPPH, and exhibitory concentration $50 \%\left(\mathrm{EC}_{50}\right)$ of $\mathrm{FRAP}_{\text {. }}$

Materials and Methods: Each sample was extracted by reflux using different polarity solvents. The extracts were evaporated using rotary evaporator. Antioxidant activities were tested using DPPH and FRAP assays, determination of total phenolic and flavonoid content were carried out by ultravioletvisible spectrophotometry and correlation with their $\mathrm{IC}_{50}$ of DPPH and $\mathrm{EC}_{50}$ of FRAP capacities were analyzed by Pearson's method.

Results: The lowest IC $_{50}$ of DPPH scavenging activity $1.14 \mu \mathrm{g} / \mathrm{ml}$ and the lowest EC $_{50}$ of FRAP capacity $49.80 \mu \mathrm{g} / \mathrm{ml}$ was given by ethanolic leaves extract of eggplant. Ethanolic leaves extract of eggplant also presented the highest total phenolic content (TPC) (8.87 g gallic acid equivalent/100 g), while the highest total flavonoid content was shown by ethyl acetate leaves extract (24.50 g quercetin equivalent/100 g). There was a significantly

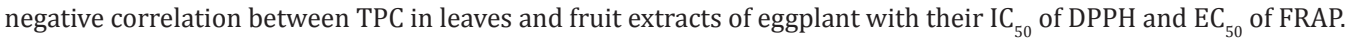

Conclusions: All different extracts of eggplant organs (except n-hexane stem extract) were categorized as a very strong antioxidant by DPPH method. Phenolic compounds in eggplant leaves and fruit extracts were the major contributor in antioxidant activities by DPPH and FRAP methods. DPPH and FRAP showed linear results in antioxidant activities of eggplant leaves, fruit and stem extracts.

Keywords: Antioxidant, 2,2-diphenyl-1-picrylhydrazyl, Ferric reducing antioxidant power, Eggplant, Solanum melongena, Organs.

(c) 2017 The Authors. Published by Innovare Academic Sciences Pvt Ltd. This is an open access article under the CC BY license (http://creativecommons. org/licenses/by/4. 0/) DOI: http://dx.doi.org/10.22159/ajpcr.2017.v10i8.18584

\section{INTRODUCTION}

Phenolic compounds included flavonoid compounds which are commonly found in many plants have various effects such as antioxidant activity and antibacterial activity [1-3]. Antioxidant can prevent the excessive of free radical in oxidative stress which can cause many degenerative diseases. Natural antioxidant can be obtained by consuming fruits and vegetables because they contain phenolic and flavonoid compounds which have antioxidant capacity [4,5]. Previous researchers expressed that phenolic and flavonoid content could be correlated to their antioxidant activities [5,6]. Eggplant (Solanum melongena) contained many flavonoid and tannin which can act as an antioxidant [7]

Antioxidant activity in many plants extracts could be determine using 2,2-diphenyl-1-picrylhydrazyl (DPPH), ferric reducing antioxidant power (FRAP), and 2,2'-azino-bis (3-ethylbenzthiazoline-6-sulfonic acid (ABTS) methods [8]. The previous researchers [4,8-10] revealed that DPPH, ABTS, and FRAP could be performed to determine antioxidant activity of fruits, vegetables, and food.

The objectives of this research were to evaluate antioxidant potential in various polarity extracts ( $n$-hexane, ethyl acetate, and ethanol) from different organs of eggplant grown in West Java-Indonesia using DPPH and FRAP assays, and correlations of total phenolic and flavonoid content with their antioxidant activities.

\section{MATERIALS AND METHODS}

Materials

DPPH, 2,4,6-tripyridyl-S-triazine (TPTZ), gallic acid, quercetin, and beta-carotene were purchased from Sigma-Aldrich (MO, USA), different organs of eggplant (S. melongena). All of other reagents were analytical grades.

\section{Preparation of sample}

Sample was collected from Lembang, West Java-Indonesia and determined in Herbarium Bandungense, School of Life Science and Technology, Bandung Institute of Technology, as $S$. melongena $\mathrm{L}$. cv. group common eggplant. Sample was three different organs of eggplant (S. melongena) which were leaves named as LV, fruit as FR, and stem as ST, were thoroughly washed with tap water, sorted while wet, cut, dried and grinded into powder.

\section{Extraction}

Extracted was performed by reflux using different polarity solvents. $300 \mathrm{~g}$ of powdered samples was extracted using n-hexane was repeated 3 times. The remaining residue was then extracted 3 times using ethyl acetate. Finally, the remaining residue was extracted 3 times using ethanol. Hence totally, there were nine extracts: Three n-hexane extracts (namely LV1, FR1, and ST1), three ethyl acetate extracts (LV2, FR2, and ST2), and three ethanolic extracts (LV3, FR3, and ST3).

\section{Antioxidant activity by DPPH assay}

Antioxidant activity by DPPH assay was conducted using Blois's method [11] with minor modification. Two ml of various concentration of each extract was added into two ml DPPH solution $50 \mu \mathrm{g} / \mathrm{ml}$ to initiate the reaction for determining a calibration curve. The absorbance was observed after 30 minutes incubation at wavelength $515 \mathrm{~nm}$ by ultraviolet-visible spectrophotometer Beckman Coulter DU 720. Ascorbic acid was used as standard, DPPH solution $50 \mu \mathrm{g} / \mathrm{ml}$ as control and methanol as a blank. Analysis was performed in triplicate for standard and each extract. Antioxidant activity was measured by evaluating the percentage of reduction of DPPH absorbance [12]. 
Inhibitory concentration $50 \%\left(\mathrm{IC}_{50}\right)$ of DPPH scavenging activity of each extract can be calculated using its calibration curve.

\section{Antioxidant capacity by FRAP assay}

FRAP solution was prepared in acetate buffer pH 3.6, using Benzi's method [13]. Two $\mathrm{ml}$ of various concentration of each extract was added into $2 \mathrm{ml} \mathrm{FRAP} \mathrm{solution} 50 \mu \mathrm{g} / \mathrm{ml}$ to initiate the reaction. After 30 minutes incubation, the absorbance was evaluated at wavelength $593 \mathrm{~nm}$. Ascorbic acid was used as a standard, acetate buffer as a blank and FRAP solution $50 \mu \mathrm{g} / \mathrm{ml}$ as a control. Analysis was conducted in triplicate for standard and each extract. Antioxidant capacity was observed based on increasing in Fe(II)-TPTZ absorbance by determining percentage of antioxidant capacity [13]. Exhibitory concentration $50 \%\left(\mathrm{EC}_{50}\right)$ of FRAP capacity of each extract can be calculated using its calibration curve.

\section{Total flavonoid content (TFC)}

Modified Chang's method [14] was used to observe TFC. The absorbance was determined at wavelength $415 \mathrm{~nm}$. Analysis was performed in triplicate for each extract. Quercetin solution $50-125 \mu \mathrm{g} / \mathrm{ml}$ was used to obtain a calibration curve. TFC was demonstrated as a percentage of total quercetin equivalent per $100 \mathrm{~g}$ extract ( $\mathrm{g} \mathrm{QE} / 100 \mathrm{~g}$ ).

\section{Total phenolic content (TPC)}

Folin-Ciocalteu reagent was conducted to determine TPC [6]. The absorbance was observed at wavelength $765 \mathrm{~nm}$. Analysis was performed in triplicate for each extract. Standard solution of gallic acid $(50-160 \mu \mathrm{g} / \mathrm{ml})$ was used to obtain a calibration curve. TPC was presented as a percentage of total gallic acid equivalent per $100 \mathrm{~g}$ extract (g GAE/100 g).

\section{Statistical analysis}

Each sample analysis was performed in triplicate. All of presented results are means ( \pm standard deviation) of at least three independent experiments. Statistical analysis using ANOVA with a statistical significance level set at $\mathrm{p}<0.05$ and post-hoc Tukey procedure was performed with SPSS 16 for Windows. Correlation between the total flavonoid and phenolic content and antioxidant activities and correlation between two antioxidant activity methods were performed using the Pearson's method.

\section{RESULTS}

\section{Antioxidant activity by DPPH and FRAP assays}

Antioxidant activity in different organs extracts of eggplant by DPPH and FRAP assays was done by evaluating $\mathrm{IC}_{50}$ of DPPH scavenging activities and $\mathrm{EC}_{50} . \mathrm{IC}_{50}$ of DPPH scavenging activities and $\mathrm{EC}_{50}$ of FRAP capacities of each extract were compared to $\mathrm{IC}_{50}$ or $\mathrm{EC}_{50}$ ascorbic acid as standard. The lowest value of $\mathrm{IC}_{50}$ or $\mathrm{EC}_{50}$ means the highest antioxidant activity.

\section{TFC in organs eggplant extracts}

TFC among three organs extracts of eggplant was presented in term of $\mathrm{QE}$ using the standard curve equation $\mathrm{y}=0.006 \mathrm{x}-0.098, \mathrm{R}^{2}=0.996$. TFC in organs eggplant extracts was varied from 0.38 to $24.50 \mathrm{~g} \mathrm{QE} / 100 \mathrm{~g}$. The lowest TFC given by ethanolic stem extract (ST3), while the highest TFC (24.50 g QE/100 g) was exposed by ethyl acetate leaves extract of eggplant (LV2) (Fig. 1).

\section{TPC in organs eggplant extracts}

TPC among different organs extracts of eggplant was exhibited in term of GAE using the standard curve equation $y=0.004 x+0.055, R^{2}=0.997$. TPC in three organs eggplant extracts had different results in the range of 1.76-8.87 g GAE/100 g (Fig. 2). Ethanolic leaves extract of eggplant (LV3) had the highest TPC (8.87 g GAE/100 g), and the lowest TPC was found in n-hexane stem extract (ST1).

Correlations between total phenolic, flavonoid content in organs eggplant extracts and $\mathrm{IC}_{50}$ of DPPH scavenging activities, $\mathrm{EC}_{50}$ of FRAP capacities

TPC in leaves and fruit extracts of eggplant had significant and negative correlation with their $\mathrm{IC}_{50}$ of DPPH scavenging activities $(r=-0.975$; $\mathrm{r}=-0.937, \mathrm{p}<0.01$, respectively) and TPC in leaves, fruit, and stem extracts of eggplant gave negative and significant correlation with their $\mathrm{EC}_{50}$ FRAP capacities $(\mathrm{r}=-0.772 ; \mathrm{r}=-0.986, \mathrm{p}<0.01, \mathrm{r}=-0.611, \mathrm{p}<0.05$, respectively) (Table 1).

\section{DISCUSSION}

The previous researchers $[15,16]$ revealed that eggplant (S. melongena) had antioxidant capacity. There was no research regarding the antioxidant activity of different organs of eggplant ( $S$. melongena) which were leaves, fruit, and stem extracted using increasing polarity solvents (n-hexane, ethyl acetate, and ethanol) and tested by DPPH and FRAP assays.

In vitro antioxidant capacity can be classified base on type of reaction, which are single electron transfer (SET) based assay and hydrogen atom transfer (HAT) based assay [17]. HAT is based on the ability of an antioxidant to quench radical by hydrogen donation, meanwhile SET based on the ability of antioxidant to transfer one electron to reduce oxidant [18]. The degree of color change (either increase or decrease of absorbance of the probe at a given wavelength) is related to the concentration of antioxidant in the sample [17]. SET and HAT mechanism almost always occur together, and mechanism that appears predominantly is influenced by ionization potential $(\Delta \mathrm{IP})$, bond dissociation energy (BDE), redox potential, $\mathrm{pH}$, and solvent $[17,18]$. HAT mechanism is predominantly for compound with $\triangle \mathrm{BDE}$ of $\sim 10 \mathrm{kcal} / \mathrm{mol}$ and $\Delta \mathrm{IP}<-36 \mathrm{kcal} / \mathrm{mol}$ and SET mechanism for compound with $\Delta \mathrm{IP}>-45 \mathrm{kcal} / \mathrm{mol}[18]$.

DPPH is free radical and show absorption at wavelength $516 \mathrm{~nm}$. DPPH in methanol gave the purple color. Antioxidant will transfer the hydrogen to DPPH to scavenge the free radical and DPPH will stable. Colors of DPPH would be changed from purple to yellow when the free radicals were scavenged by antioxidant [19]. Decreasing in the absorption of DPPH correlates with the ability of an antioxidant to scavenge the free radical DPPH. IC ${ }_{50}$ of DPPH scavenging activity is a concentration of sample or standard that can inhibit $50 \%$ of DPPH radical activity. The lowest $\mathrm{IC}_{50}$ means had the highest antioxidant

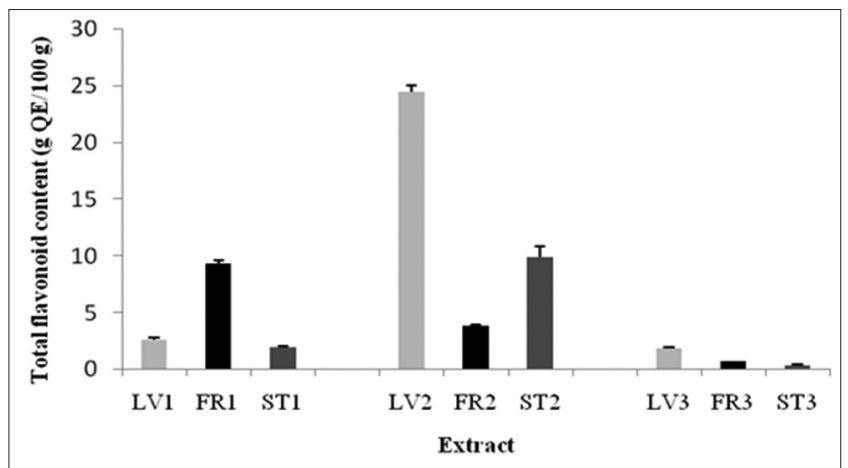

Fig. 1: Total flavonoid content in organs eggplant extracts $(n=3)$

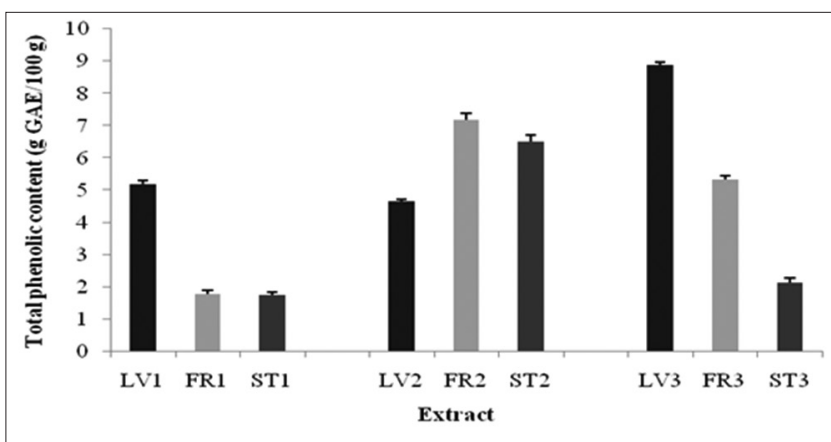

Fig. 2: Total phenolic content in organs eggplant extracts $(n=3)$ 
activity. $\mathrm{IC}_{50}$ was used to determine antioxidant activity of the sample was compared to standard [20]

In the human body, the presence of Fe(III) can be related with free radical. In this reaction exhibit that Fe(III) will react with antioxidant and antioxidant will reduce Fe(III) to Fe(II) and then Fe(II) reacts with one reagent and the complex will give absorption at certain wavelength. FRAP reagent is ferric (III) chloride which was combined with TPTZ in acetate buffer $\mathrm{pH}$ 3.6. Antioxidant will reduce Fe(III) to Fe(II) if it has reduction potential lower than $0.77 \mathrm{~V}$ (reduction potential of $\mathrm{Fe}(\mathrm{III}) / \mathrm{Fe}(\mathrm{II})=0.77 \mathrm{~V})$. Complex of Fe(II) - TPTZ shows blue color and gave characteristic absorption at wavelength $593 \mathrm{~nm}$. Intensity of blue color depends on amount of Fe(III) which is reduced to Fe(II) and gives complex with TPTZ. EC $_{50}$ of FRAP capacity is concentration of sample or standard that can exhibit $50 \%$ of FRAP capacity [20].

$\mathrm{IC}_{50}$ of DPPH scavenging activities and $\mathrm{EC}_{50}$ of FRAP capacities in different organs extracts of eggplant were presented in Figs. 3 and 4.

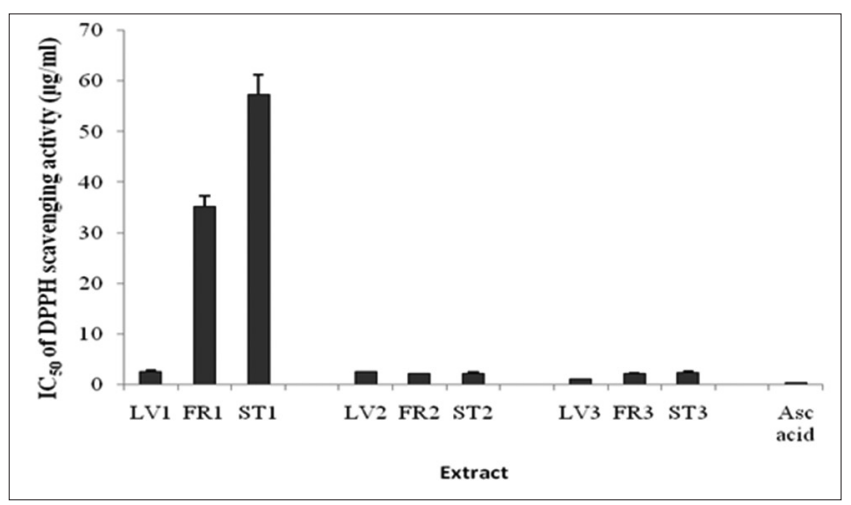

Fig. 3: Inhibitory concentration $50 \%$ of 2,2-diphenyl-1picrylhydrazyl in organs eggplant extracts $(n=3)$

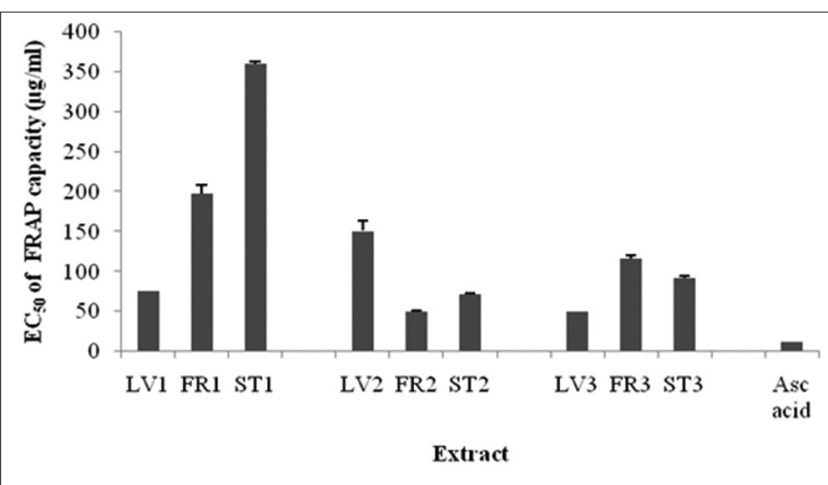

Fig. 4: Exhibitory concentration $50 \%$ of ferric reducing antioxidant power capacities in organs eggplant extracts $(n=3)$
The $\mathrm{IC}_{50}$ of DPPH scavenging activities and $\mathrm{EC}_{50}$ of FRAP capacities in different organs extracts of eggplant were compared to $\mathrm{IC}_{50}$ or $\mathrm{EC}_{50}$ of ascorbic acid standard. The lowest value of $\mathrm{IC}_{50}$ or $\mathrm{EC}_{50}$ means the highest antioxidant activity. Sample which had an $\mathrm{IC}_{50}$ or $\mathrm{EC}_{50}$ lower than $50 \mu \mathrm{g} / \mathrm{ml}$ was a very strong antioxidant, $50-100 \mu \mathrm{g} / \mathrm{ml}$ was a strong antioxidant, $101-150 \mu \mathrm{g} / \mathrm{ml}$ was a medium antioxidant, while a weak antioxidant with $\mathrm{IC}_{50}$ or $\mathrm{EC}_{50}>150 \mu \mathrm{g} / \mathrm{ml}[11]$.

In this study $\mathrm{IC}_{50}$ of DPPH of scavenging activities of all extracts varied from 1.14 to $57.26 \mu \mathrm{g} / \mathrm{ml}$ which were categorized as very strong antioxidant (except $\mathrm{n}$-hexane stem extract of eggplant $57.26 \mu \mathrm{g} / \mathrm{ml}$ ), while the ethanolic organs extract of eggplant (leaves, fruit, and stem) in the range of $1.14-2.38 \mu \mathrm{g} / \mathrm{ml}$. Previous research by Somawathi et al. [21], studied regarding antioxidant of fresh pulp of different color peel of eggplant. This study reported that water extract of S1 (purple peel color with no lines) had the highest antioxidant activity which presented by the lowest IC $_{50}$ of DPPH $(3.51 \mathrm{mg} / \mathrm{ml})$. In this study used eggplant with purple peel with no line and one of the sample was fruit of eggplant, which included peel and pulp of eggplant. It was different result between ethanolic fruit extract of eggplant in this study and water pulp extract in the previous study [21]. In the previous study showed IC I0 $_{5}$ of DPPH $3.51 \mathrm{mg} / \mathrm{ml}$ which was categorized as very weak antioxidant, while in this study denoted $\mathrm{IC}_{50}$ of DPPH $2.16 \mu \mathrm{g} / \mathrm{ml}$ and can be classified as very strong antioxidant. The difference between both of studies may be since the previous study used fresh pulp, while in this study used dry fruit. The other reasons may be different solvent for extraction process, different site location, etc. The previous study [16], demonstrated that 75\% ethanolic leaves extract of different harvest time and different site location gave different result in antioxidant activities by DPPH and ABTS methods. The previous result revealed that sample which collected at $\leq 80$ days in flowering gave the highest antioxidant activity by DPPH method (53.1 $\mu \mathrm{g}$ L-ascorbic acid equivalent (ASC)/mg extract) and ABTS method (73.9 $\mu$ g Trolox/mg), while sample from $45^{\circ} \mathrm{N}$ location exhibited the highest antioxidant by DPPH $56.5 \mu \mathrm{g}$ ASC/mg extract and the highest by ABTS method (75.6 $\mu \mathrm{g}$ Trolox/mg) compared to the others sample. Research by Jung et al. [22] exposed that 70\% ethanolic extract of peel extract of eggplant from Korea had the highest antioxidant activity which showed the lowest IC $_{50}$ DPPH $(0.98 \mathrm{mg} / \mathrm{ml})$, compared to the other parts of eggplant (calyx, leaves, pulp, and stem). Meanwhile, the water calyx extract had the highest antioxidant activity ( IC $_{50}$ DPPH $0.49 \mu \mathrm{g} / \mathrm{ml}$ ) compared to the other parts (leaves, pulp, peel, and stem). The $70 \%$ ethanolic stem extract and water stem extract of eggplant had $\mathrm{IC}_{50}$ DPPH $13.13 \mathrm{mg} / \mathrm{ml}$ and $26.20 \mathrm{mg} / \mathrm{ml}$, respectively. It was contrast with the present study which showed ethanolic stem extract of eggplant had $\mathrm{IC}_{50}$ DPPH $2.38 \mu \mathrm{g} / \mathrm{ml}$.

The previous research [15] represented that antioxidant activity of fruit extract from six varieties of eggplant using percentage of DPPH radical scavenging activity. Methanolic extract of sample GBL-1 gave the highest percentage of DPPH radical scavenging activity (40.35\%), and the lowest activity was given by methanolic extract of sample GJB-3 (25.17\%). Study by Sultana et al. [23] presented that percentage

Table 1: Pearson's correlation coefficient of total phenolic, flavonoid content in organs eggplant extracts with their IC ${ }_{50}$ of DPPH scavenging activities and $\mathrm{EC}_{50}$ of FRAP capacities

\begin{tabular}{|c|c|c|c|c|c|}
\hline \multirow[t]{2}{*}{ Antioxidant parameter } & \multicolumn{5}{|c|}{ Pearson's correlation coefficient $(r)$} \\
\hline & TFC & TPC & EC $_{50}$ FRAP LV & EC $_{50}$ FRAP FR & EC $_{50}$ FRAP ST \\
\hline $\mathrm{IC}_{50} \mathrm{DPPH} \mathrm{LV}$ & $-0.975^{* *}$ & $0.499^{\text {ns }}$ & $0.661^{*}$ & & \\
\hline $\mathrm{IC}_{50}^{50} \mathrm{DPPH} F \mathrm{FR}$ & $-0.937^{* *}$ & $0.930^{* *}$ & & $0.884^{* *}$ & \\
\hline $\mathrm{IC}_{50}^{50} \mathrm{DPPH}$ ST & $-0.559^{\mathrm{ns}}$ & $-0.358^{\mathrm{ns}}$ & & & $0.995^{* *}$ \\
\hline $\mathrm{EC}_{50}^{50}$ FRAP LV & $-0.772^{*}$ & $0.969^{* *}$ & & & \\
\hline $\mathrm{EC}_{50}^{50}$ FRAP FR & $-0.986^{* *}$ & $0.673^{*}$ & & & \\
\hline $\mathrm{EC}_{50}^{50}$ FRAP ST & $-0.611^{*}$ & $-0.415^{\mathrm{ns}}$ & & & \\
\hline
\end{tabular}

*Significant at $\mathrm{p}<0.05,{ }^{* *}$ Significant at $\mathrm{P}<0.01$. IC ${ }_{50}$ DPPH: Inhibitory concentration $50 \%$ 2,2-diphenyl-1-picrylhydrazyl scavenging activity, EC ${ }_{50}$ FRAP: $_{\text {Exhibitory }}$ concentration $50 \%$ ferric reducing antioxidant power capacity, LV: Leaves of eggplant, FR: Fruit of eggplant, ST: Stem of eggplant, TPC: Total phenolic content, TFC: Total flavonoid content, ns: Not significant 
of DPPH scavenging activity of methanolic peel extract of $S$. melongena was higher than its methanolic flesh extract.

Antioxidant activities can be presented by percentage of DPPH scavenging activity, and the value was compared to percentage of DPPH scavenging activity of ascorbic acid as standard. The value of percentage of DPPH scavenging activity of ascorbic acid did not achieve $100 \%$ because there was still residual yellow color in solution after giving hydrogen atom to DPPH by antioxidant $[24,25]$. The percentage of DPPH scavenging activity could not present the real antioxidant activities because the higher concentration or dose of extract or sample did not always give the higher percentage of DPPH scavenging activities. It will give linear result in some concentration or some doses only. This condition can be happened in extract or sample which contained more than one compound. The extract consisted of many compounds, and not all of compound has antioxidant activities, may be some of them act as an antagonist of antioxidant activities. The compounds will act as an antagonist of antioxidant activities if their minimum effective dose has been reached. Hence, this reason can explain why in lower dose extract can give higher activities than higher dose extract.

In FRAP method, antioxidant capacity was determined the ability of antioxidant to reduce $\mathrm{Fe}(\mathrm{III})$ to $\mathrm{Fe}(\mathrm{II})$ and then Fe(II) react with TPTZ to give an intense blue color Fe ${ }^{2+}$-TPTZ complex. This method is fast, reproducible, and nonspecific [13]. Any compound which has lower redox potential than $0.77 \mathrm{~V}$ (redox potential of $\mathrm{Fe}^{3+} / \mathrm{Fe}^{2+}$ ) can be detected by FRAP assay $[13,26]$.

Antioxidant capacity of water pulp extract of different color of eggplant using FRAP assay was reported in the previous study [21], which denoted that water pulp extract of sample S1 (purple peel color with no lines) had the highest antioxidant activity $(6.77 \mathrm{mmol}$ $\mathrm{Fe}^{2+} / \mathrm{g}$ fresh weight) compared to sample S2 (light purple peel with lines), S3 (dark purple peel with lines), S4 (pink color), and S5 (purple with green lines). It was similar to their result by DPPH assay. However, it was different from ABTS assay, which reported that water peel extract of sample S3 (dark purple peel color with lines) had the highest antioxidant activity which gave the highest percentage of ABTS scavenging activity (40.45\%). In this study, ethanolic leaves extract had the highest antioxidant activity by FRAP assay $(49.80 \mu \mathrm{g} / \mathrm{ml})$ compared to ethanolic fruit and stem extracts. Previous research [27] found that methanolic extract of boiled fruit of Solanum torvum had lower IC $_{50}$ of ABTS scavenging activity $(80.3 \mu \mathrm{mol}$ Trolox/g extract) compared to fresh fruit $226.1 \mu \mathrm{mol}$ Trolox/g extract. Research by Loganayaki et al. [28] exposed that methanolic fruit extract of Solanum nigrum had highest antioxidant activity among the chloroform, methanolic and acetone of leaves and fruit parts of Solanum americanum and $S$. torvum by ABTS method.

Flavonoid may have antioxidant effect as hydrogen-donating compound, metal chelating ion, single oxygen transfer, and singlet oxygen quencher [29]. Basically, structural requirement for hydrogen donating and metal chelating is related to o-dihydroxy structure in the ring B, C-2-C-3 double bond and oxo group at C-4 [29]. In this study, ethyl acetate leaves extract of eggplant gave the highest TFC $24.50 \mathrm{~g} \mathrm{QE} / 100 \mathrm{~g}$. TFC in ethanolic extract of leaves, fruit, and stem of eggplant was 1.91, 0.72 , and $0.38 \mathrm{~g} \mathrm{QE} / 100 \mathrm{~g}$, respectively. It was similar to the previous research which demonstrated that TFC in 70\% ethanolic leaves extract was the highest $8 \mathrm{mg}$ catechin equivalent (CE)/g extract compared to the other parts. The result also similar to its water leaves extract which expressed the highest TFC (5.20 mg CE/g extract) compared to calyx, peel, pulp and stem extracts [22]. Padmashree et al. [30] reported that methanol-water $(4: 1)$ leaves extract of $S$. nigrum had the highest TFC (1.51 g/100 g) compared to methanol extract $(1.01 \mathrm{~g} / 100 \mathrm{~g})$, ethyl acetate extract $(0.65 \mathrm{~g} / 100 \mathrm{~g})$, and water extract $(0.54 \mathrm{~g} / 100 \mathrm{~g})$. Study by Kandoliya et al. [15] figured that methanolic pulp extract of sample GBL-1 showed the highest TFC (13.25 mg QE/100 g) among six varieties of eggplant. While Piao et al. [16] reported that total flavonoid aglycone in sample from $45^{\circ} \mathrm{N}$ location was the highest compared to other location. It was similar to sample that collected at $\leq £ 80$ days in flowering presented the highest total flavonoid aglycone. Previous research [31] regarding methanolic fruit extract of five varieties of eggplant presented that SM1 (uniform, purple, and moderate size) had the highest TFC $3.95 \mathrm{~g} \mathrm{CE} / 100 \mathrm{~g}$ compared to SM2 (white and green, moderate size), SM3 (long green), SM4 (striped green, moderate size), and SM5 (uniform, pale green, and small size).

Antioxidant capacity can be related to TPC $[6,32]$. Flavonoids, tannins, and phenolic acids are included in phenolic groups. Benzoic acid has lower antioxidant than cinnamic acid [33]. Ortho and para hydroxyl substitution have stronger antioxidant capacity [34]. The previous study presented that methanolic fruit extract of sample GBL-1 had the highest TPC compared to the other varieties (JBGR-1, GOB-1, GJB-2, GJB-3, and $\mathrm{GBH}-2)$. In this study, TPC varied from 1.76 to $8.87 \mathrm{~g} \mathrm{GAE} / 100 \mathrm{~g}$, while TPC in the ethanolic extract in the range of 2.13-8.87 $\mathrm{g} \mathrm{GAE} / 100 \mathrm{~g}$ and ethanolic leaves extract showed the highest TPC. It was different from research by Jung et al. [22] which represented that 70\% ethanolic peel extract gave the highest TPC (55.19 mg GAE/g extract) and also its water peel extract showed the highest TPC (54.94 mg GAE/g extract) compared to the other parts. Study by Somawathi et al. [21] expressed that TPC in water pulp extract of sample S3 (dark purple peel with lines) was the highest (61.11 mg GAE/100 g) compared to the other sample. Purple color in eggplant can be correlated with anthocyanin content in eggplant. Anthocyanin is one of phenolic compounds in plant. Hence, it can be supposed that dark purple color in eggplant sample S3 from anthocyanin compound which showed high phenolic content.

Coefficient of Pearson correlation was significantly negative if $-0.61 \leq r \leq-0.97$ and significantly positive if $0.61 \leq r \leq 0.97$ [8]. The lowest IC $_{50}$ of DPPH scavenging activity and $\mathrm{EC}_{50}$ of FRAP capacity will give the highest antioxidant activity. Increasing in TFC and TPC may influence increasing in antioxidant activities, which was exposed by lower $\mathrm{IC}_{50}$ of DPPH scavenging activity and/or $\mathrm{EC}_{50}$ of FRAP capacity. Hence, the good correlation between TPC and TFC with IC ${ }_{50}$ of DPPH or $\mathrm{EC}_{50}$ of FRAP was significantly negative correlation [20].

Study by Somawathi et al. [21] expressed that TPC in water pulp extracts of eggplant with different peel color had a negative and significant correlation with their $\mathrm{IC}_{50}$ of DPPH scavenging activities. It was similar to this study which showed that TPC in all of organs extracts of eggplant (except stem extract) had significantly negative correlation with their antioxidant activities by DPPH and FRAP methods. While their TFC value had no significant correlation with their antioxidant by DPPH and FRAP methods. Research by Loganayaki et al. [28] showed that TPC in fruit and leaves extracts of $S$. nigrum and $S$. torvum had no significant correlation with their percentage of DPPH, ABTS scavenging activities and FRAP capacities.

This study showed that TPC in leaves and fruit extract of eggplant had significant and negative correlation with their $\mathrm{IC}_{50}$ of DPPH $(\mathrm{r}=-0.975$; $\mathrm{r}=-0.937, \mathrm{p}<0.01$, respectively) and $\mathrm{EC}_{50}$ of FRAP ( $\mathrm{r}=-0.772 ; \mathrm{r}=-0.986$, $\mathrm{p}<0.01$, respectively). Based on the Pearson's coefficient correlation it can be predicted that phenolic compounds in leaves and fruit of eggplant were the major contributor in their antioxidant activities by DPPH and FRAP methods. IC I $_{50}$ of DPPH scavenging activities of all organs extracts (leaves, fruit, and stem) had significantly positive correlation with their $\mathrm{EC}_{50}$ of FRAP capacities ( $\mathrm{r}=0.661, \mathrm{p}<0.05 ; \mathrm{r}=0.884, \mathrm{r}=0.995, \mathrm{p}<0.01$, respectively), hence the result presented that the two antioxidant methods (DPPH and FRAP) gave linear result for leaves, fruit, and stem extracts of eggplant.

It can be seen in Fig. 1 that ethyl acetate leaves extract of eggplant (LV2) gave the highest TFC (24.50 g QE/100 g) while ethanolic stem extract (ST3) showed the lowest TFC (0.38 g QE/100 g), but $\mathrm{IC}_{50}$ of DPPH of LV2 $(2.57 \mu \mathrm{g} / \mathrm{ml})$ was similar to $\mathrm{IC}_{50}$ of DPPH of ST3 $(2.38 \mu \mathrm{g} / \mathrm{ml})$. It can be predicted that many flavonoid compounds in LV2 react with reagent that be used in TFC determination, which 
was flavonoid aglycone semipolar and or flavonoid monoglycoside that have ortho di $-\mathrm{OH}$ at $\mathrm{C} 3^{\prime}-\mathrm{C}^{\prime},-\mathrm{OH}$ at $\mathrm{C} 3-$ oxo function at $\mathrm{C} 4$, and or $-\mathrm{OH}$ at $\mathrm{C} 5$ - oxo function at $\mathrm{C} 4$. Only ortho di -OH at C3'-C4' in flavonoid will contribute in high antioxidant activity. The weakness of this reaction is any compound which has ortho di-OH at benzene ring can react with aluminum (III) chloride and form a complex. The same reaction can occur in any compound which has ortho di $-\mathrm{OH}-\mathrm{OCH}_{3}$ in benzene ring. All compounds that explanation above soluble in ethyl acetate. Hence, this reason can explain why ST3 which had TFC $0.38 \mathrm{~g}$ QE/100 g only can give similar antioxidant activities with LV2. The flavonoid compounds which soluble in ethanol stem extract (ST3) were flavonoid monoglycoside and or flavonoid diglycoside. It can be supposed that ST3 contained many flavonoid compounds which had ortho di-OH at C3'-C4' and a double bond at $\mathrm{C} 2-\mathrm{C} 3$, and have high antioxidant activities.

TFC in ethyl acetate fruit extract (FR2) 3.8 QE/100 g was higher than TFC in ethanolic leaves extract (LV3) $1.91 \mathrm{~g} \mathrm{QE} / 100 \mathrm{~g}$, meanwhile EC $_{50}$ of FRAP capacity of FR2 $(50.05 \mu \mathrm{g} / \mathrm{ml})$ was similar to $\mathrm{EC}_{50}$ of FRAP of LV3 $(49.80 \mu \mathrm{g} / \mathrm{ml})$. Based on the result it can be predicted that many flavonoid compounds in LV3 had reduction potential lower than $0.77 \mathrm{~V}$ (reduction potential of $\mathrm{Fe}(\mathrm{III}) / \mathrm{Fe}(\mathrm{II})$ ), since they can reduce many Fe(III) to Fe(II) and form a blue color with TPTZ, while many flavonoid compounds in FR2 had reduction potential greater than $0.77 \mathrm{~V}$.

TPC in ethanolic leaves extract of eggplant (LV3) $8.87 \mathrm{~g} \mathrm{GAE} / 100 \mathrm{~g}$ was the highest TPC among all of the organs extract. LV3 also denoted the highest antioxidant by DPPH and FRAP assays, which showed the lowest IC $_{50}$ of DPPH $(11.14 \mu \mathrm{g} / \mathrm{ml})$ and EC $_{50}$ of FRAP $(49.80 \mu \mathrm{g} / \mathrm{ml})$. It revealed that phenolic compounds in LV3 had high antioxidant activities, may be LV3 consisted of many cinnamic acids which give higher antioxidant than benzoic acid, and many flavonoid compounds with $\mathrm{OH}$ in certain position which influence high antioxidant activities

\section{CONCLUSION}

Different results can be given by various methods, so for determining antioxidant activities should be carried out by different methods in parallel. All different organs extracts of eggplant $S$. melongena L. (except n-hexane stem extract) can be categorized as very strong antioxidant using DPPH assay. TPC in leaves and fruit extracts of eggplant had a significantly negative correlation with their $\mathrm{IC}_{50}$ of DPPH scavenging activities and $\mathrm{EC}_{50}$ of FRAP capacities. Phenolic compounds in leaves and fruit extracts of eggplant were the major contributor in their antioxidant activity by DPPH and FRAP methods. There was a linear correlation between $\mathrm{IC}_{50}$ of DPPH scavenging activities and $\mathrm{EC}_{50}$ of FRAP capacities in all organs extracts of eggplant (leaves, fruit, and stem). Leaves, fruit, and stem of eggplant (S. melongena) have many benefits to prevent oxidative stress and potential as sources of natural antioxidant for further exploitation.

\section{REFERENCE}

1. Hodnick WF, Milosavljevic EB, Nelson JH, Pardini RS. Electrochemistry of flavonoids. Relationships between redox potentials, inhibition of mitochondrial respiration, and production of oxygen radicals by flavonoids. Biochem Pharmacol 1988;37(13):2607-11.

2. Mokbel MS, Hashinaga F. Antibacterial and antioxidant activities of banana (Musa, AAA CV. Cavendish) fruits peel. Am J Biochem Biotechnol 2005;1(3):125-31.

3. Sebei K, Gnouma A, Herchi W, Sakouhi F, Boukhchina S. Lipids, proteins, phenolic composition, antioxidant and antibacterial activities of seeds of peanuts (Arachis hypogaea 1 ) cultivated in Tunisia. Biol Res 2013;46(3):257-63.

4. Pellegrini N, Serafini M, Colombi B, Del Rio D, Salvatore S, Bianchi M, et al. Total antioxidant capacity of plant foods, beverages and oils consumed in Italy assessed by three different in vitro assays. J Nutr 2003;133(9):2812-9.

5. Zielinski AA, Haminiuk CW, Alberti A, Nogueira A, Demiate IM,
Granato D. A comparative study of the phenolic compounds and the in vitro antioxidant activity of different Brazilian teas using multivariate statistical techniques. Food Res Int 2014;60:246-54.

6. Pourmorad F, Hosseinimehr SJ, Shahabimajd N. Antioxidant activity, phenol and flavonoid content of some selected Iranian medicinal plants. Afr J Biotechnol 2006;5(11):1142-5.

7. Saleh GS. Chemical detection of some active compounds in egg plant (Solanum melongena) callus as compared with fruit and root contents. Int J Curr Microbiol Appl Sci 2015;4(5):160-5.

8. Thaipong K, Boonprakob U, Crosby K, Zevallos LC, Byrne DH. Comparison of ABTS, DPPH, FRAP, and ORAC assays for estimating antioxidant activity from guava fruit extracts. J Food Compost Anal 2006;19:669-75.

9. Arya N, Prakash OM, Verma AK, Vivekanand, Pant AK. Variation in antioxidant potential of Curcuma longa L. Collected from different ecological niches of western Himalayan region. Int J Pharm Pharm Sci 2015;7(7):85-90

10. Settharaksa S, Madaka F, Chakree K, Charoenchai L. Total phenolic and flavonoid contents and antioxidant properties of Thai traditional herbal. Int J Pharm Pharm Sci 2014;6(9):564-6.

11. Blois MS. Antioxidant determination by the use of stable free radicals. Nature 1958;181:1199-2000.

12. Bedawey AA. Characteristics of Antioxidant Isolated from Some Plants Sources. Shibin El-Kom: Cairo; 2010. p. 1-11.

13. Benzi IF, Strain JJ. The ferric reducing ability of plasma (FRAP) as a measure of "antioxidant power": The FRAP assay. Anal Biochem 1996;239:70-6.

14. Chang CC, Yang MH, Wen HM, Chern JC. Estimation of total flavonoid content in propolis by two complementary colorimetric methods. J Food Drug Anal 2002;10:178-82.

15. Kandoliya UK, Bajaniya VK, Bhadja NK, Bodar NP, Golakiya BA. Antioxidant and nutritional components of egg plant (Solanum melongena L.) fruit grown in Saurastra region. Int J Curr Microbiol Appl Sci 2015;4(2):806-13.

16. Piao XM, Chung JW, Lee GA, Lee JR, Cho GT, Lee HS, et al. Variation in antioxidant activity and flavonoid aglycones in eggplant (Solanum melongena L.) germplasm. Plant Breed Biotechnol 2014;2(4):396-403.

17. Apak R, Gorinstein S, Böhm VK, Schaich MK. Methods of measurement and evaluation of natural antioxidant capacity/activity: IUPAC technical report. Pure Appl Chem 2013;85:957-98.

18. Prior RL, Wu X, Schaich K. Standardized methods for the determination of antioxidant capacity and phenolics in foods and dietary supplements. J Agric Food Chem 2005;53:4290-302.

19. Li XC, Wang XZ, Chen DF, Chen SZ. Antioxidant activity and mechanism of protochatechuic acid in vitro. J Funct Food Health Dis 2011;1:232-44

20. Fidrianny I, Johan Y, Sukrasno. Antioxidant activities of different polarity extracts from three organs of makrut lime (Citrus hystrix DC) and correlation with total flavonoid, phenolic, carotenoid content. Asian J Pharm Clin Res 2015;8(4):239-43.

21. Somawathi KM, Rizliya V, Wijesinghe DG, Madhujith WM. Antioxidant activity and total phenolic content of different skin coloured brinjal (Solanum melongena). Trop Agric Res 2014;26:152-61.

22. Jung EJ, Bae MS, Jo EK, Jo YH, Lee SC. Antioxidant activity of different parts of eggplant. J Med Plants Res 2011;5(18):4610-5.

23. Sultana B, Hussain Z, Hameed M, Mushtaq M. Antioxidant activity among different parts of aubergine (Solanum melongena L.) Pak J Bot 2013;45(4):1443-8.

24. Barreira JC, Ferreira IC, Oliveira MB, Pereira JA. Effects of different phenols extraction conditions on antioxidant activity of almond (Prunus dulcis) fruits. J Food Biochem 2009;33:763-76.

25. Miliauskas G, Venskutonis PR, van Beek TA. Screening of radical scavenging activity of some medicinal and aromatic plant extracts. Food Chem 2004;85:231-7.

26. Wicks LK, Wood LG, Garg ML. Methodology for the determination of biological antioxidant capacity in vitro: A review. J Sci Food Agric 2006;86:2046-56.

27. Nithiyanantham S, Varadharajan S, Siddhuraju P. Differential effects of processing methods on total phenolic content, antioxidant and antimicrobial activities of three species of Solanum. J Food Drug Anal 2012;20(4):844-54.

28. Loganayaki N, Siddhuraju P, Manian S. Antioxidant activity of two traditional Indian vegetables: Solanum nigrum L. and Solanum torvum L. Food Sci Biotechnol 2010;19:121-7.

29. Amic D, Amic DD, Beslo D, Rastija V, Lucic B, Trinajstic N. SAR and QSAR of the antioxidant activity of flavonoids. Curr Med Chem 
2007; 14:827-45

30. Padmashree A, Sharma GK, Semwal AD, Mahesh C. Antioxygenic activity of Solanum nigrum L. Leaves in sun flower oil model system and its thermal stability. Food Nutr Sci 2014;5:1022-9.

31. Akanitapichat P, Phraibung K, Nuchklang K, Prompitakkul S. Antioxidant and hepatoprotective activities of five eggplant varieties. Food Chem Toxicol 2010;48(10):3017-21.

32. Mongkolsilp S, Pongbupakit I, Sae-Lee N, Sitthithaworn W. Radical scavenging activity and total phenolic content of medicinal plants used in primary health care. SWU J Pharm Sci 2004;9(1):32-5.

33. Heim KE, Tagliaferro AR, Bobilya DJ. Flavonoid antioxidants: Chemistry, metabolism and structure-activity relationships. J Nutr Biochem 2002;13:572-84.

34. Sroka Z, Cisowski W. Hydrogen peroxide scavenging, antioxidant and anti-radical activity of some phenolic acids. Food Chem Toxicol 2003;41:753-8. 